\title{
Characterization of $\mathrm{Cr}$ doped diamond-like carbon films and research on mechanical properties \\ Youyu Fan ${ }^{1,2, a}$, Guang $\mathrm{Li}^{1, \mathrm{~b}}$ and Yuan $\mathrm{Xia}^{1, \mathrm{c}}$ \\ ${ }^{1}$ Institute of mechanics, Chinese Academy of Sciences, Beijing 100190, China \\ ${ }^{2}$ Graduate University of Chinese Academy of Sciences, Beijing, 100049, China \\ afanyouyu@imech.ac.cn, 'Ighit@imech.ac.cn, ${ }^{\mathrm{c} x i a @ i m e c h . a c . c n}$
}

Keywords: Cr-DLC films; Internal stress; Nanohardness; XPS

\begin{abstract}
Diamond-like carbon (DLC) films have been extensively studied for more than a decade due to their unique combination of properties. The internal compressive stress affects their adhesion and preventing wide usage of these films. Metal-containing DLC films are expected to relax internal stress. The present work focused on the synthesis, chemical bond and mechanical property characterization of Cr-containing DLC films. The films thickness, internal stress and composition were characterized by scanning electron microscopy, optical interferometry and X-ray photoelectron spectroscopy respectively. Incorporation of Cr into DLC causes an initial internal stress reduction and subsequent stabilization around $0.5 \mathrm{GPa}$. The hardness behavior was found to depend on $\mathrm{Cr}$ content. Films with less than 7.36 at.\% $\mathrm{Cr}$ (no formation of $\mathrm{C}-\mathrm{Cr}$ bond) showed a dramatically hardness reduction compared to pure DLC films. Above 7.36 at.\% $\mathrm{Cr}(\mathrm{C}-\mathrm{Cr}$ bond formed) the hardness increases above $12 \mathrm{GPa}$.
\end{abstract}

\section{Introduction}

Diamond-like carbon (DLC) films have been extensively studied for more than a decade and have been applied in tribological, biomedical, and optical fields due to their unique properties such as high hardness, chemical inertness, high wear resistance, low friction coefficient, and high optical transparency in the infra-red [1-5]. The internal stresses that develop during synthesis affect adhesion which results in unstable performance of DLC films under work condition. Thereby, most scientific research about DLC films have been concentrated to metal-containing such as Ti [6, 7], W [8, 9], Al $[10,11]$ etc. containing DLC films to reduce internal stress. Whereas, the doping metal elementals affects other performance of DLC films (hardness etc.) inevitably while reduce the internal stress [12-14]. Chromium is an outstanding candidate for doping into DLC films since it is a carbide former and has complex influence on the mechanical properties.

The purpose of the present work was to set a study of mechanical properties of Cr-DLC films as a function of $\mathrm{Cr}$ content. The overall objective is to develop a better understanding of composition-property relations through the chemical bond state of $\mathrm{C}$ in Cr-DLC films, which is influenced by the incorporated element $\mathrm{Cr}$, thus optimize the mechanical properties of DLC films from the composition perspective.

\section{Experimental Details}

Cr-doped DLC films investigated in this work were prepared by a co-deposition system, which consists of a vacuum cathodic arc (VCA) source using $99.99 \%$ graphite target and a mid-frequency magnetron sputtering (MS) source using $99.99 \%$ chromium target. The VCA and MS source are located face-to-face designed in a cylindrical chamber as the specimens are placed on a center platform and rotated during deposition process. The distance between the substrate and the VCA as well as the MS source is about $220 \mathrm{~mm}$. Mechanical filtration was used to avoid fused carbon droplet generated from the graphite target while plasma could passed through the holes $(\Phi 1.5 \mathrm{~mm})$ uniformly distributed on the filtration. $500 \pm 15$ thick Si wafers were used as substrate. Besides, slides of size 18 $\mathrm{mm} \times 18 \mathrm{~mm}$ with $150 \pm 20 \mu \mathrm{m}$ thickness were used as substrates to estimate the internal stress from 
the observed curvature of the film/substrate composite by Stoney equation[15, 16]. The curvature of the film/substrate was determined by optical interferometry. All substrates were cleaned ultrasonically in acetone and ethanol respectively, and then dried in air. Before deposition, the vacuum chamber was pumped to a base pressure of $5.0 \times 10^{-3} \mathrm{~Pa}$ and the substrates were sputtered for 15 min with bias voltage of $900 \mathrm{~V}$; Ar gas flow rate was set steadily at $40 \mathrm{sccm}$ during deposition process of $30 \mathrm{~min}$. The VCA current was set as $60 \mathrm{~A}$, and MS current was adjusted from 0 A to $0.6 \mathrm{~A}$ in order to obtain different $\mathrm{Cr}$ content DLC films; the bias voltage applied to the substrate was constant of $35 \mathrm{~V}$.

Scanning electron microscopy (SEM, JEOL JSM-5800) was conducted to observe the thickness of films. The elemental composition and chemical bonding of $\mathrm{C}$ and $\mathrm{Cr}$ were investigated by $\mathrm{X}$-ray photoelectron spectroscopy (XPS, PHI Quantera). The top contaminated surface layer was removed using $\mathrm{Ar}^{+}$sputtering for $2 \mathrm{~min}$. The hardness of Cr-DLC films were measured by the nano-indentation (XP nano-mechanical testing system, MTS Corporation) using a Berkovich diamond indenter. The measurement was operated under the continuous stiffness measurement (CSM) mode. In the CSM depth sensing test, the maximum indentation depth was $250 \mathrm{~nm}$, and the characteristic hardness was chosen in the depth of about $70 \mathrm{~nm}$.

\section{Results and Discussion}

The deposition conditions used to synthesize Cr-DLC films with different $\mathrm{Cr}$ content were presented in Table 1.

All the Cr-DLC samples were characterized by XPS. The composition of films could be calculated from the area under each peak of $\mathrm{C}, \mathrm{Cr}, \mathrm{O}$ and the corresponding atomic sensitivity factor. The compositions of films are shown in Table 2. The main element is $\mathrm{C}$ and it is clear that the $\mathrm{Cr}$ content increases from 4.22 at.\% to 17.93 at.\% with increased magnetron current. Besides, the sample 4 and 5 synthesized by different magnetron sputtering current but contains nearly the same $\mathrm{Cr}$ content around 11 at.\%.

Table 1. Deposition parameters used to synthesize Cr-DLC films

\begin{tabular}{|c|c|c|}
\hline Sample & $\begin{array}{l}\text { Deposition rate } \\
{[\mathrm{nm} / \mathrm{min}]}\end{array}$ & $\begin{array}{l}\text { Magnetron } \\
\text { current [mA] }\end{array}$ \\
\hline 1 & 13.67 & 0 \\
\hline 2 & 17.28 & 200 \\
\hline 3 & 13.89 & 300 \\
\hline 4 & 12.80 & 400 \\
\hline 5 & 16.92 & 500 \\
\hline 6 & 14.80 & 600 \\
\hline
\end{tabular}

Table 2. Composition of Cr-DLC films obtained by XPS

\begin{tabular}{llll}
\hline Sample & Cr [at.\%] & C [at.\%] & O [at.\%] \\
\hline 2 & 4.22 & 90.81 & 4.97 \\
3 & 7.36 & 87.07 & 5.57 \\
4 & 10.89 & 86.32 & 2.79 \\
5 & 11.32 & 84.59 & 4.09 \\
6 & 17.93 & 80.26 & 1.82 \\
\hline
\end{tabular}

Fig. 1 shows the $\mathrm{C}$ 1s peak of the Cr-DLC films with $\mathrm{Cr}$ content 10.89 at.\% and 11.32 at.\%, and each exhibits a major peak at a binding energy around $284.5 \mathrm{eV}$. The $\mathrm{C} 1 \mathrm{~s}$ peak can be deconvoluted into four components with binding energies 284, 284.9, 283 and $286 \mathrm{eV}$ corresponding to sp2 C-C, sp3 C-C, chromium carbide and $\mathrm{C}-\mathrm{O}$ bond. In order to acquire the $\mathrm{C}-\mathrm{Cr}$ concentration of all films, $\mathrm{C}$ 1s peaks of all films are deconvoluted and the results are shown in Fig.2. The C-Cr bond doesn't emerge until the $\mathrm{Cr}$ content is higher than 7.36 at.\%. Sample 4 and 5 contains nearly the same $\mathrm{Cr}$ content, 10.89 at $\%$ and 11.32 at.\% respectively, but contains different $\mathrm{C}-\mathrm{Cr}$ bond concentration with $6.58 \%$ and $10.77 \%$ respectively. Higher energies of ions are expected to promote the reaction of incoming $\mathrm{Cr}$ and $\mathrm{C}$ atoms, i.e. the bombardment energy of ion could affect the structure of films significantly. 

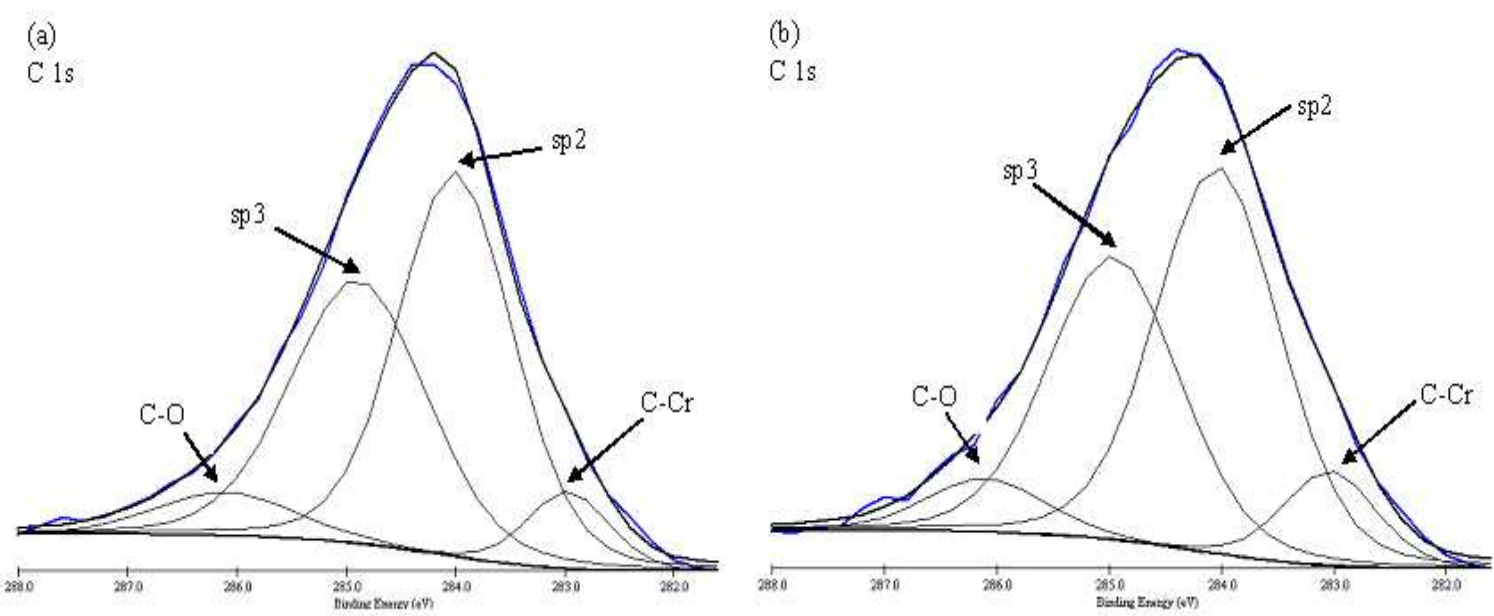

Fig.1. C 1s XPS results of Cr-DLC films: (a) Cr content 10.89 at.\% and (b) Cr content 11.32 at.\%.

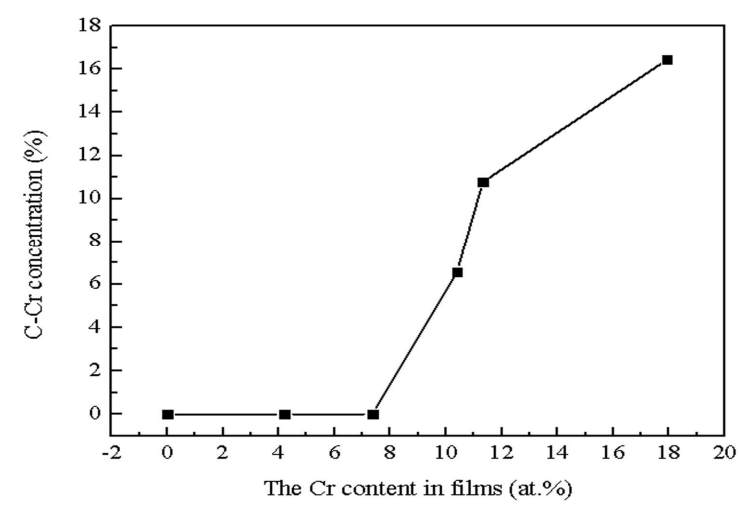

Fig.2. C-Cr chemical bond concentration of DLC film and Cr-DLC films as a function of $\mathrm{Cr}$ content.

The internal stress of DLC film and Cr-DLC films are showed in Fig.3(a). The internal stress dramatically decrease from $2.78 \mathrm{GPa}$ to $0.37 \mathrm{GPa}$ and then increase to $0.74 \mathrm{GPa}$ as the $\mathrm{Cr}$ content exceeds 11.32 at.\%. Thus, chromium is sufficient to reduce the internal stress of DLC films by influence the chemical state of $\mathrm{C}$ such as $\mathrm{sp} 3 / \mathrm{sp} 2$ ratio descending and the formation of chromium carbide; the intrinsic reasons of internal stress reducing should be investigated further. Dai et al. [12] synthesized $\mathrm{Cr}$ doped a-C:H films and found that the internal stress decreased at first and then increased when $\mathrm{Cr}$ content is higher than 12.1 at.\%, which is a little higher than our results of 11.32 at. $\%$ because of the differences in the synthesized process.

(a)

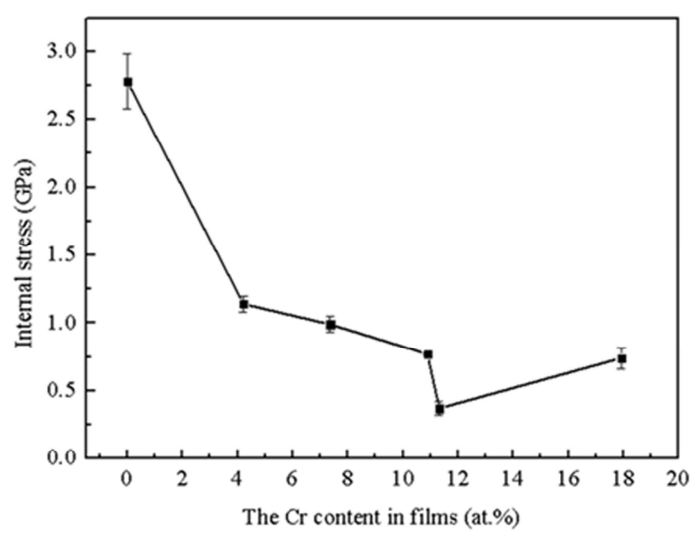

(b)

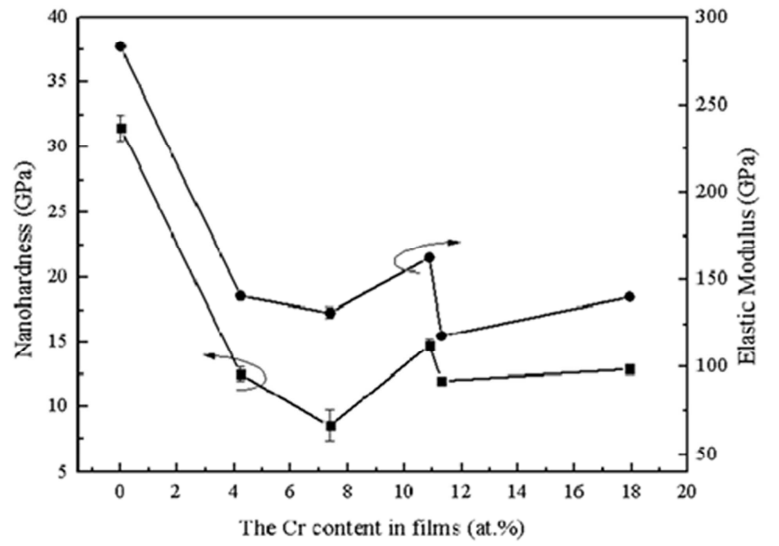

Fig.3. Micromechanics properties of DLC film and Cr-DLC films as a function of Cr content (a) the internal stress, (b) nanohardness and elastic modulus.

Fig.3(b) shows the nanohardness and elastic modulus of DLC and Cr-DLC films. The nanohardness of films decrease from $31.56 \mathrm{GPa}$ to $8.55 \mathrm{GPa}$ with the $\mathrm{Cr}$ content lower than 7.36 at.\%. Whereas, the hardness increase to higher than $12 \mathrm{GPa}$ with the $\mathrm{Cr}$ content exceeds 7.36 at.\%. 
Considering the concentration of C-Cr bond, we found that the nanohardness of films decrease when no $\mathrm{C}$-Cr bond formed, yet increase when $\mathrm{Cr}$ content exceeds 7.36 at.\%, i.e. C-Cr bond begins to emerge in the carbon network. Therefore, it can be deduced that the formation of chromium carbide could increase the hardness of films. Chen et al. [17] found that there was a progressive rise in hardness as the $\mathrm{W}$ target end current increases and the trend was due to the formation of carbide nanoparticles dispersed in the carbon matrix. The trend of elastic modulus behaves similar to that of hardness.

\section{Conclusions}

Cr-doped DLC films were synthesized by cathodic vacuum arc and mid-frequency magnetron sputtering system. The $\mathrm{Cr}$ content was varying from 4.22 at.\% to 17.93 at.\%. The films with more than 7.36 at.\% Cr were found containing C-Cr bond in DLC network. Incorporation of Cr into DLC causes an initial internal stress reduction and subsequent stabilization around $0.5 \mathrm{GPa}$. The hardness behavior was found to depend on $\mathrm{Cr}$ content or $\mathrm{C}-\mathrm{Cr}$ bond. Films with less than 7.36 at.\% $\mathrm{Cr}$ (no formation of $\mathrm{C}-\mathrm{Cr}$ bond ) showed a dramatically hardness reduction compared to pure DLC films. Above 7.36 at.\% $\mathrm{Cr}$ (C-Cr bond formed) the hardness increases above $12 \mathrm{GPa}$. While presenting appropriate $\mathrm{C}-\mathrm{Cr}$ bond deriving from carbide phase, the films with about 11 at.\% $\mathrm{Cr}$ achieve comparable mechanical properties to the rest of DLC.

\section{Acknowledgements}

The authors are grateful to the Opening Fund of State Key Laboratory of Nonlinear Mechanics (2012) and Youth Exploration Fund of Key Laboratory of Mechanics in Advanced Manufacturing (2012), Institute of Mechanics, Chinese Academy of Sciences for the financial support.

\section{References}

[1] J. Robertson, Thin Solid Films 383/1-2 (2001) 81.

[2] N. Ali, Y. Kousar, T.I. Okpalugo, V. Singh, M. Pease, A.A. Ogwu, J. Gracio, E. Titus, E.I. Meletis, M.J. Jackson, Thin Solid Films 515/1 (2006) 59.

[3] J. Choi, K. Ishii, T. Kato et al. , Diamond and Related Materials 20/5-6 (2011) 845.

[4] A. Grill, Surface \& Coatings Technology 94-5/1-3 (1997) 507.

[5] A. Grill, Thin Solid Films 355 (1999) 189.

[6] X.Z. Ding, B.K. Tay, S.P. Lau, P. Zhang, X.T. Zeng, Thin Solid Films 408/1-2 (2002) 183.

[7] D. Sheeja, B.K. Tay, C.Q. Sun, Y.Q. Fu, Journal of Materials Science 38/3 (2003) 421.

[8] Y.H. Cheng, B.K. Tay, S.P. Lau, X. Shi, Surface \& Coatings Technology 146-147 (2001) 398.

[9] C. Strondl, N.M. Carvalho, J.T.M. De Hosson, T.G. Krug, Surface and Coatings Technology 200/1-4 (2005) 1142.

[10]D. Sheeja, B.K. Tay, J.Y. Sze, L.J. Yu, S.P. Lau, Diamond and Related Materials 12 (2003) 2032.

[11]P. Zhang, B.K. Tay, S.P. Lau, Diamond and Related Materials 12/10-11 (2003) 2093.

[12] W. Dai, G. Wu, A. Wang, Diamond and Related Materials 19/10 (2010) 1307.

[13] K.K. Mistry, A. Morina, A. Neville, Wear 271/9-10 (2011) 1739.

[14]D.Y. Wang, K.W. Weng, S.Y. Hwang, Diamond and Related Materials 9/9-10 (2000) 1762.

[15]H. Dimigen, C.-P. Klages, Surface and Coatings Technology 49/1-3 (1991) 543.

[16] G.G. Stoney, Proceedings of the Royal Society A: Mathematical, Physical and Engineering Sciences 82/553 (1909) 172.

[17]X. Chen, Z. Peng, Z. Fu, S. Wu et al. , Surface and Coatings Technology 205/12 (2011) 3631. 